\title{
К ВОПРОСУ ОБ АЗОТЕ ОРГАНИЧЕСКОГО ВЕЩЕСТВА ДИКТИОНЕМОВОГО СЛАНЦА *
}

\section{Л. НАППА}

А. ФОМИНА,

доктор химических наук

В ранее опубликованной статье $\left[{ }^{2}\right]$ было показано, что при гидролизе керогена диктионемового сланца от 15 до $30 \%$ азота переходит в растворимые формы. При качественном анализе гидролизата, методом бумажной хроматографин, в нем былю ндентифицированы 9 аминокислот, в том числе шесть моноаминокарбоновых: глицин, $\boldsymbol{a}$-аланин, изолейцин, лейцин, валин и $\gamma$-аминомасляная кислота; одна оксимоноаминокислота - серин, одна моноаминодикарбоновая кислота - глутаминовая и одна ароматическая аминокислота - фенилаланин.

Установление в керогене диктионемового сланца значительного количества гидролизуемых форм азота, а главное идентификация аминокислот, свойственных широкому кругу растительных и животных белков указывало на несомненную целесообразность дальнейшего углубления исследований.

Из наименований идентифицированных аминокислот следует, чте все они относятся к моноаминокислотам. Однако известно, что гидролиз белков минеральными кислотами ['] сопровождается дезамидированием амидов, например глутамина, аспаргина и др. с выделением аммиака, разрушением (в результате окисления) триптофана, серина и т. д.

Выявление амидного азота возможно при определении форм гидролизованного азота. С целью проведения этого анализа была поставлена новая серия опытов гид ролиза керогена диктионемового сланца и проведены анализы гндролизатов. Результаты вышеуказанных исследований излагаются ниже.

\section{Экспериментальная часть}

Для определения форм растворимого азота гидролиз керогена осуществлялся $33 \%$-ной серной кислотой при $95^{\circ}$ на водяной бане и при $105^{\circ}$ на воздушной бане Гидролиз проводился 24 и 48 часов. Концентрат сланца (обогащение производилось центрифугированием в тяжелых жидкостях, водных растворах хлористого цинка с плотностью $1,555 \mathrm{z}^{2} \mathrm{~cm}^{3}$ ) брался в количестве от 50 до 100 , что соответствовало $22,5-45,0$ г керогена. Серная кислота бралась по отношению к концентрату сланца в количестве $10: 1$.

В гидролизате, после отделения от нерастворимой части, определялось, общее содержание азота по Къельдалю, аммиачный и диаминокислотный азот определялись по методике А. Н. Белозерского и Н. И. Проскурякова [ $\left.{ }^{3}\right]$.

Для определения аммиачного азота проба гидролизата обрабатывалась окисью магния под уменьшенным давлением, в пределах 10-20 мм рт. ст. Отгонка аммиака производилась не выше $40^{\circ}$.

После отделения сульфата магния в фильтрате определялся диаминокислотный

* Сообщение второе. 
азот. Для этого фильтрат подкислялся соляной кислотой и к нему добавлялся насыщенный водный раствор фосфорновольфрамовокислого натрия (4 г на 5 мл). Раствор с белым осадком, образующимся с диаминокислотами, после нагревания в течение часа на водяной бане оставлялся еще на 72 часа при комнатной температуре. Затем его фильтровали через беззольный фильтр (синяя лента). Осадок на фильтре тщательно промывали $2 \%$-ной соляной кислотой, подсушивали на воздухе и вместе с фильтром переносили в колбу Къельдаля для обычного определения азота.

Фосфорновольфрамовокислый натрий не взаимодействует с моноаминокислотами, при этом анализе они определяются по разности между общим азотом и суммой аммначного и диамннокислотного азота

При проведении опытов гидролиза и последующего анализа гидролизатов на вышеуказанные формы азота выявились большие расхождения между параллельными определениями. Тщательное проведение самого гидролиза (в закрытой аппаратуре с установлением поглотителя на аммиак), точная выдержка температуры и времени гидролиза не дали необходимой сходимости между параллельными опытами. Поскольку при опубликовании исследований по определению форм азота в тех или иных ископаемых не упоминалось о том, что между параллельными определениями не имеется обычной -сходимости, то было проделано много разных варнантов гидролиза, в том числе и анализ с добавлением определенного количества известного азотсодержащего вещества.

В просмотренной нами ли-

\section{Таблица I}

тературе только в «Практическом руководстве по биохимии растений» 1934 г. А. Р. Кизеля [4] указывается, что определение форм азота в гидролизатах белков дает колеблющнеся результаты в параллельных определениях из-за мелких трудноучитываемых условий гидро лиза. На опыте определения форм азота в гидролизате керогена диктионемового, сланца (55\% мннеральной части) это полностью подтвердилось. В связи с этим, из многочисленных трудоемких анализов, были взяты только результаты более близкие между собой и из них выведены средние значения, которые и приведены в табл. 1.

Средние значения для отдельных форм азота показывают, что по меньшей мере $25-30 \%$ гидролизованного азота оказывается уже в форме

Результаты анализа форм азота в кислотных гидролизатах диктионемового сланца (при $100-105^{\circ}$ )

\begin{tabular}{|c|c|c|c|c|}
\hline & \multicolumn{3}{|c|}{$\begin{array}{c}\text { Время гидролиза, } \\
\text { часы }\end{array}$} & \multirow{2}{*}{ 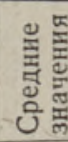 } \\
\hline & 24 & 48 & $24^{*}$ & \\
\hline $\begin{array}{c}\text { Формы азота на гидроли- } \\
\text { зованную часть, \% }\end{array}$ & & & & \\
\hline $\begin{array}{l}\text { 1. Аммиачный азот } \\
\text { 2. Диаминокислотный }\end{array}$ & 31,0 & 26,8 & 27,2 & 28,3 \\
\hline 3. Мот & 25,6 & 33,0 & 33,8 & 30,8 \\
\hline азот (по разности) & 43,4 & 40,2 & 39,0 & 40,9 \\
\hline От исходного азота, \% & & & & \\
\hline $\begin{array}{l}\text { 1. Выход гидролизован- } \\
\text { ного азота } \\
\text { 2. Негидролизуемого }\end{array}$ & 18,0 & 14,0 & 17,0 & 16,3 \\
\hline $\begin{array}{l}\text { азота в остатке } \\
\text { 3. Расхождение между } \\
\text { исходным азотом и } \\
\text { суммой его после гид- } \\
\text { ролиза }\end{array}$ & 80,0 & 83,0 & 81,0 & 81,3 \\
\hline
\end{tabular}

* Анализ проведен с добавлением аргинина, глутаминовой кислоты и шавелевокислого аммония.

аммиака, тем самым устанавливалось, что в условиях опыта из керогена освобождаются неустойчивые в кислой среде азотсодержащие соединения, отщепляющие его в виде аммнака. Кроме того результаты показали, что в составе гидролизата, помимо ранее установленного моноаминокислотного азота (бумажной хроматографией), порядка $30 \%$ его находится в виде диаминокислотной формы. Хотя при анализе отдельных гидролизатов имелись расхождения, однако во всех случаях устанавливалось наличие всех трех форм азота. Это обязывало возвратиться к более тщательным качественным поискам аминокислот в гидролизате, в частности необходимо было выяснить ранее неустановленные основные аминокислоты (диаминокислоты). 


\section{Второй этап качественного анализа кислотных гидролизатов керогена диктионемового сланца}

На втором этапе качественных анализов аминокислотного состава гидролизатов нсследование проводилось на концентрате сланца флотационного обогащения. ${ }^{*}$ Считая на абсолютно сухое вещество жонцентрат содержал $48,6 \%$ золы прокаливания и $0,5 \%$ минеральной $\mathrm{CO}_{2}$.

Элементарный состав керогена был следующим **: $\mathrm{C}-69,9 \%, \mathrm{H}-6,9 \%, \mathrm{~N}-2.1 \%$, $\mathrm{S}-2,2 \%$ и $\mathrm{O}_{2}$ (по разности) $-18,9 \%$.

Гидролиз керогена осуществлялся $6 \mathrm{H} \mathrm{HCl}$ при $105^{\circ}$ в течение 24 часов.

-Навеска концентрата сланца соответствовала 264,7 г керогена. Кислота бралась к концентрату в отношении $10: 1$. Первичный гидролизат содержал большое количество солей и был сильно оқрашен. Соляная кислота из гидролизата отгонялась в ва-

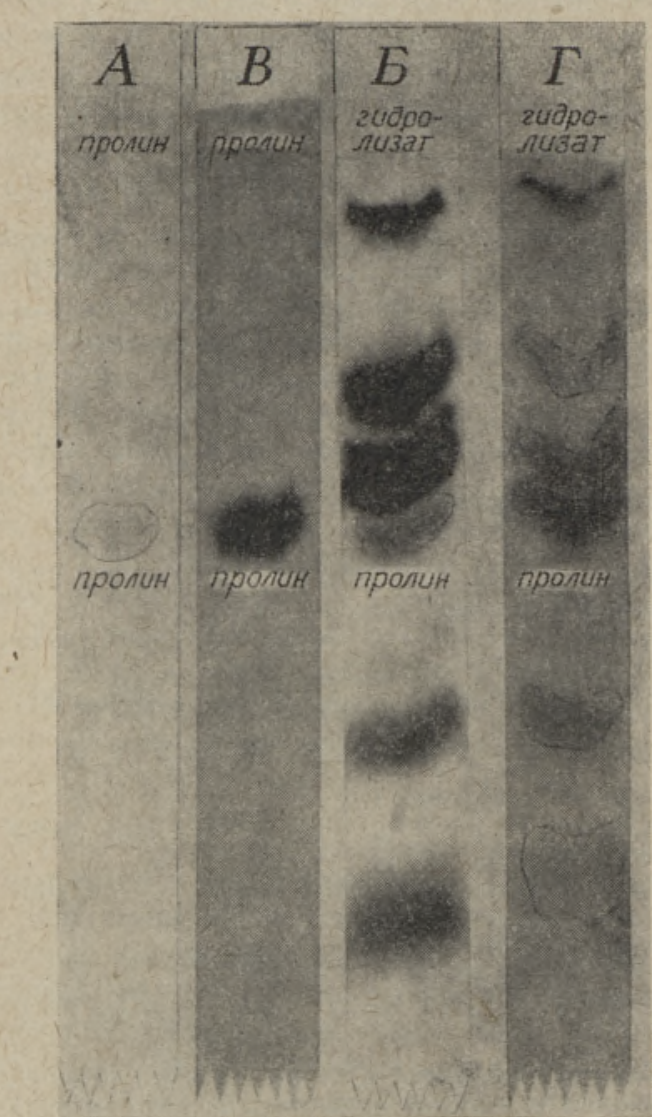

Фото 1. Нисходящая хроматография. Растворитель - н-бутанол, ледяная уксусная кислота, вода $(4: 1: 5)$. кууме при температуре не выше $45^{\circ}$. Сухой остаток снова растворялся в воде и отгонка повторялась. После трехкратного повторения вышеуказанных операций сухой остаток был растворен в воде и перенесен в стакан, где объем раствора был доведен. до 1,5 л. Для удаления солей железа и алюминия раствор обрабатывался водным аммиаком $(1: 1)$ до $\mathrm{pH}$ раствора $7,1-7,5$ (5). После 24 ча сового отстаивания гидраты окисей железа и алюминия отделялись фильтрованием. Осадок на фильтре тщательно промывался подогретой дистиллированной водой. Раствор и промывные воды подвергались дистилляции в вакууме. Остаток после дистилляции представлял собой белую с слегка желтоватым оттенком массу. Для окончательного обессоливания ос таток растворялся в 150 мл бидистиллированной воды и затем очнщался на колонке с катионитом КУ-2 в Н-форме. Әлюнрование аминокислот пронзводилось $2 \mathrm{H}$ водным раствором аммиака. Последний удалялся из элюата выпариванием в вакууме. Конечный объем аминокислот был доведен до 12 мл.

Для консервирования амннокислот к раствору было дөбавлено 2,5 мл 10\%-ного водного раствора изопропилового спирта. Раствор аминокислот хранился в холодильном шкафу при температуре около $4^{\circ}$.

* Обогащение произведено аспнрантом В. И. Ерусенко на аппаратуре и с помощью сектора обогатительных процессов Института хнмни АН ЭССР.

** Анализ пронзведен В. И. Ерусенко. 
На первом этапе касественной бумажной хроматографии оставались нендентифицированными пятна веществ, реагировавших с нингидрином. Одно из них предположительно можно было отнести за счет пролина. Однако недостаточная очистка гидролизатов от солей затрудняла идентификацию. Обессоленные растворы аминокислот. к тому же с более высокой концентрацией последних, позволили приступить к выяснению наличия пролина.

Для хроматографирования была использована одномерная нисходящая бумажная хроматография [2]. Для контроля брался раствор чистого пролина с конщентраций $10 \mu$. В качестве растворителя использовалась смесь н-бутанола, ледяной уксусной кислоты и бидистиллированной воды $(4: 1: 5)$. Хроматографирование осуществлялось на полосах хроматографической бумаги Шлейхер и Шелл размером $50 \times 4 \mathrm{~cm}$. На 2 полосы наносился гидролизат в количестве 0,1 мл, а на две другие - свидетель в количестве 0,02 мл. Процедура хроматографирования производилась, как описано ранее [2]. Одна пара хроматограмм (гидролизата и контрольная) проявлялись $2 \%$-ным раствором нингидрина в ацетоне [6], вторая пара $2 \%$-ным раствором изатина в этиловом спирте [†]. Пятна, соот ветствующие по величине $R_{f}$ и окраске пролину, были получены на обеих хроматограммах гидролизата керогена. Нингидрин образовал желтое пятно, которое при высушивании хроматограмм (при $60^{\circ}$ ) переходило в коричневатое. Изатин дал ярко синюю окраску. Полученные хроматограммы приведены на фото 1. Таким образом, кроме ранее установленных али. фатических и ароматических аминокислот в гидролизате керогена диктионемового сланца была идентифицирована гетероциклическая аминокислота (пирролидин-2-карбоновая).

Для установления диаминокислот были опробованы различные виды бумажной хроматографии. Круговая бумажная хроматография $\left.{ }^{8}\right]$ не дала положительных результатов. Положительное, но недостаточно яркое пятно, соответствующее (в сравнении со свидетелями) только аргинину было получено при одномерной нисходящей хроматографии на бумаге «Ленинградская медленная» с фенольно-буферным растворителем (рН буфера 12, соотношение 1:1). Снимок хроматограммы приведен на фото 2. Более интенсивная окраска пятна аргинина была получена при применении двухмерной восходящей хроматографии $\left[9,{ }^{10}\right]$, где в качестве растворителя в одном направлении использовалась смесь метанола, бидистиллированной воды и пиридина, в отношениях соответственно $80: 20: 4$. Во втором направлении разделение

Фото 2. Нисходящая хроматография. Растворитель фенолбуферный раствор $(1: 1)$. Прояви. тель - $2 \%$-ный раствор нингидрина.

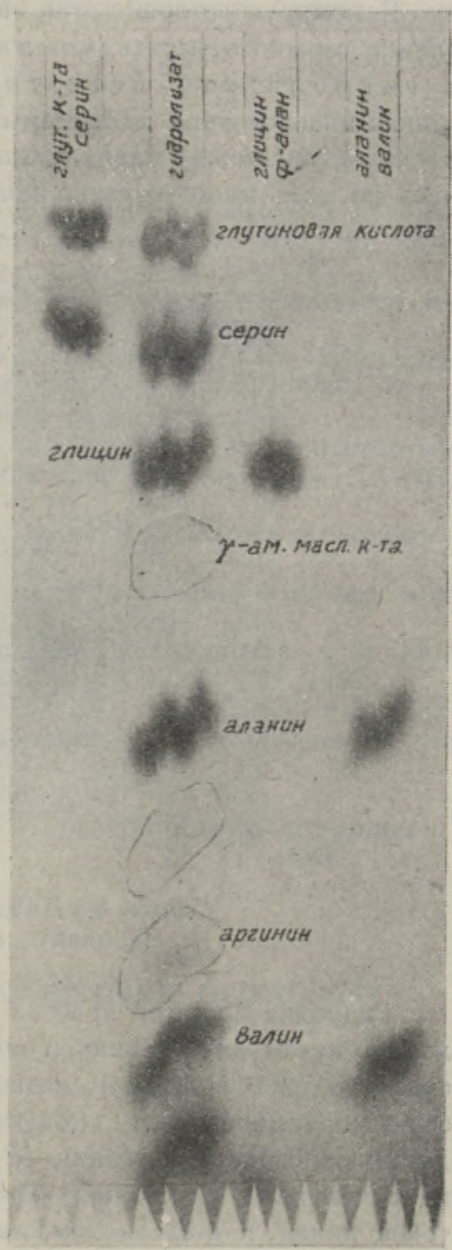

производилось смесью н-бутанола, метилэтилкетона, бидистиллированной воды и диэтиламина, в соотношениях $40: 40: 20: 5$. Проявление пронзводилось 1\%-ным раствором нингидрина. Снимок хроматограммы приведен на фото 3. Сравнение двухмерной хроматограммы с кар๋той Редфилда [ $\left.{ }^{9}\right]$ показало, что на двухмерной хроматограмме из 
числа идентифицированных установлено 10 аминокислот, не обнаружена только $\gamma$-аминомасляная кислота, вероятно из-за ее низкой концентрации в смеси.

Следовательно, из диаминокислот, как при одномерной, так и двухмерной хроматографии был установлен только аргинин ( $\alpha$-амино- $\delta$-гуанидиновалерьяновая кислота)

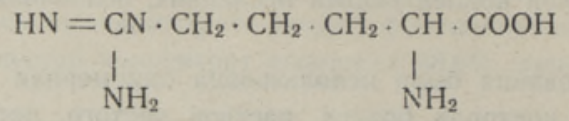

Как следует из формулы аргинина, он отличается высоким содержанием азота $(32,2 \%)$. При нисходящей хроматографии с растворителями крезол-буфер вблизи стартовой линии, с н-бутанолом, ледяной уксусной кислотой, бидистиллированной водой (4:1-5) обычно выше аргинина (ближе к стартовой линии) оставалось неидентифицированное пятно соединения, которое реагировало как с нингидрином, так и изатином (см. фото 1). Возможно это пятно соответствует тоже основной аминокислоте, но с более длинной углеродной цепью, чем аргинин, как, например $\boldsymbol{\alpha}, \boldsymbol{\varepsilon}-$ диаминопимелиновая кислота, выделенная из ряда бактерий ['].

Резюмируя второй. этап исследований гидролизатов керогена диктионемового сланца, можно отметить, что экспери ментально показано присутствие в гидролизате всех трех форм азота, т. е. кроме ранее установленной моноаминокислотной, также аммиачной и диаминокислотной. Несмотря на значительные расхождения между параллельными анализами, диаминокислотная форма устанавливалась во всех многочисленно полученных гидролизатах.

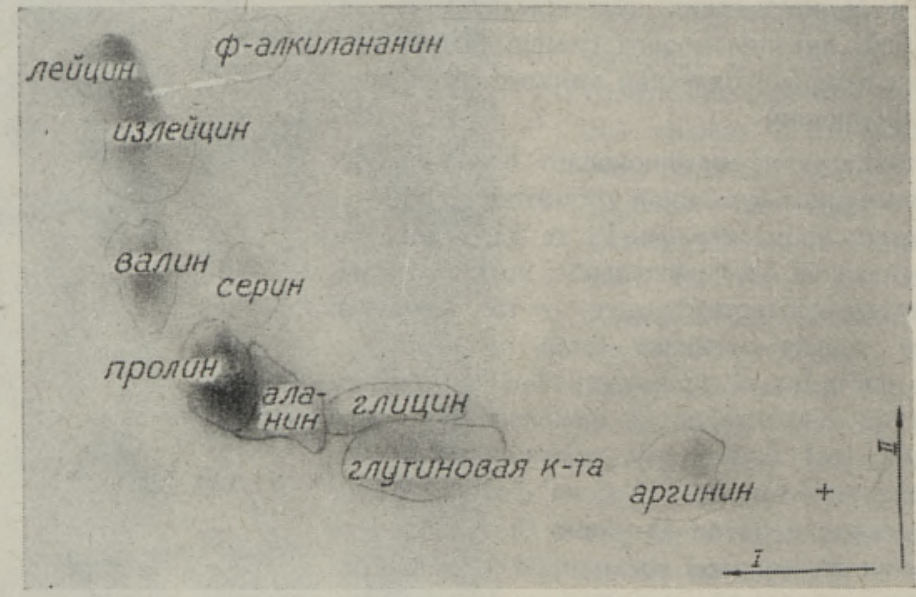

Фото 3. Двухмерная восходящая хроматография.

Проявитель - 1\%-ный раствор нингидрина.

Гидролиз большой навески керогена $(264,7$ 2) и тшательное обессоливание гидролизата путем двухстадийной очистки (с использованием при доочистке ионообменной смолы ҚУ-2 в Н-форме), позволили дополнительно идентифищировать гетерошиклическую моноаминокислоту (пироллидин-2-карбоновую-пролин), а также установить одну диаминокислоту - аргинин ( $\alpha$-амино- $\delta$-гуанидиновалерьяновая кислота). Кроме того, на одномерных нисходящих хроматограммах, элюировавшихся крезолом, вблизи стартовой линии, и н-бутанолом, ледяной уксусной кислотой, бидистиллированной водой $(4: 1: 5)$, недалеко от стартовой линии, оставалось неидентифицированное пятно соединения (или нескольких), реагировавшего как с нингидрином, так и с изатином. Судя по литературным данным и содержанию диаминокислотной формы азота в гидролизате (около $30 \%$ ), можно допустить, что оно относится к основным более длинноцепочным аминокислотам, чем установленный аргинин, 
В итоге двух этапов исследований, качественной бумажной хроматографии сернокислых и солянокислых гидролизатов керогена диктионемового сланца было уста новлено 11 аминокислот и одно неидентифицированное пятно. Установленные кислоты относятся к следующим классам:

алифатические моноаминокарбоновые кислоты - глицин, аланин, лейцин, изолейцин, валин и $\gamma$-аминомасляная кислота;

алифатическая оксиаминокарбоновая кислота - серин;

алифатическая моноаминодикарбоновая кислота - глутаминовая;

алифатическая диаминокарбоновая кислота - аргинин;

гетероциклическая аминокислота - пролин;

ароматическая аминокислота - фенилаланин.

Состав дополнительно установленных аминокнслот еще раз подтверждает участие в структуре керогена диктионемового сланца продуктов частичного разложения, характерных для широко распространенных белков как в мире животных, так и растений.

Результаты количественного анализа смессй аминокислот и прнмерное определение доли азотсодержащих структурных элементов в керогене диктионемового сланца будут приведены в сводной статье.

\title{
ЛИТЕРАТУРА ,
}

1. А. М а йстер, Биохнмия аминокислот, ИЛ, М., 1961.

2. Л. Н а п п а, А. С. Фоми н а, К вопросу об азоте органического вещества диктионемового сланца. Изв. АН ЭССР, Сер. фнз.-мат. и техн. наук, № 3, 195-204, 1960.

3. А. Н. Белозерский и Н. И. Проскуряков, Практическое руководство по биохимии растений, М., 1951.

4. А. Р. К и зель, Практическое руководство по биохимии растений, отд. III. Белкн и продукты их гидрологического распада и превращения, М.-Л., 1934.

5. И. М. Кольтгоф, Е. Б. Сенд эл, Количественный анализ, М., 1938.

6. В. Л. Кре тович, Ж. В. У спен ск а я, Синтез фенилаланина из фенилпировиноградной кислоты в гомогенатах из проростков гороха. Биохимия, т. XXIII, вып. 2, 1958 .

7. А. Н. Боярки н, Разноцветное проявление аминокислот на бумажных хроматограммах. Физиология растений, т. 3, вып. 4, 1956.

8. K. V. G iri, N. A. N. R a o, A technique for the identification of amino acids separated by circular paper chromatography. Nature, 169, 923, 1952.

9. R. R. Redfield, Two dimensional paper chromatographic systems with high resolving power for amino acids. Biochem. et Biophys. Acta 10, 344, 1953.

10. Н. М. Сисакян, Э. Н. Везингер, П. Г. Гаркави, Г. Я. Кивтян, Простой метод разделения аминокислот распределительной хроматографии на бумаге. ДАН АН СССР, т. 46, вып. 2, 1954.

$\begin{array}{cc}\text { Институт химии } & \text { Поступила в редакцию } \\ \text { Академии наук Эстонской ССР } & 27 . \text { IV } 1963\end{array}$

\section{DIKTUONEEMAKILDA ORGAANILISE AINE LAMMMASTIKU OLEMUSEST}

(II osa)

\author{
L. Nappa \\ A. Fomina, \\ keemiateaduste doktor
}

\section{Resümee}

Artiklis esitatakse lämmastikuühendite vormide määramise andmed diktüoneemakilda kerogeeni väävelhappelistes hüdrolüsaatides ning monoamiino- ja diamiinohapete kvalitatiivse paberkromatograafia teise etapi tulemused. Eri lämmastikuvormide keskmised väärtused olid järgmised: ammoniakaalset läınmastikku $28,3 \%$, diamiinohappelist lämmastikku $30,8 \%$, monoamiinohappelist lämmastikku (vahest) $41,1 \%$. Lisaks varem iden- 
tifitseeritud amiinohapetele $\left[{ }^{2}\right]$ identifitseeriti veel heterotsükliline amiinohape proliin ja alifaatne diamiinohape arginiin. Oldse identifitseeriti 11 amiinohapet ja tehti kindlaks identifitseerimata ühend (või ühendid), mis reageerib nii ninhüdriiniga kui ka isatiiniga arvatavasti diamiinohape, millel on pikem süsinikuahel kui arginiinil.

\section{Eesti NSV Teaduste Akadeemia Keemia Instituut}

Saabus toimetusse 26. IV 1963

\title{
ZUR FRAGE VOM STICKSTOFF DES ORGANISCHEN TEILS DES DIKTYONEMASCHIEFERS
}

\section{Mitteilung II}

\author{
L. Nappa, A. Fomina
}

\section{Zusammenfassung}

In vorliegender Arbeit wurden die Formen der Stickstoffverbindungen des Diktyonemaschiefers in Hydrolysaten der Schwefelsäure untersucht und die zweite Etappe der qualitativen Untersuchungen der Mono- und Diaminosäuren durchgeführt.

Die Durchschnittswerte der Stickstoffverbindungen waren: ammoniakalischer Stickstoff $28,3 \%$, diaminosäurischer Stickstoff - 30,8\% und monoaminosäurischer Stickstoff $41,1 \%$ (aus dem Unterschied).

Zusätzlich zu den früher identifizierten Aminosäuren wurden noch zwei identifiziert: eine heterozyklische - Prolin - und eine aliphatische - Arginin.

Im allgemeinen wurden 11 Aminosäuren identifiziert, ausserdem eine nicht identifizierte Verbindung gefunden, die sowohl mit Ninhydrin als auch mit Isatin reagiert wahrscheinlich eine Diaminosäure mit längerer Kohlenstoffkette als Arginin. 